\title{
Vorschau auf die Hölderlin-Ausstellung 2020
}

Das Hölderlin-Gedenkjahr 2020 wird unter den kulturellen Aktivitäten des Landes Baden-Württemberg, aber auch darüber hinaus in der ganzen literarischen Welt von großer Bedeutung sein. Die Württembergische Landesbibliothek wird den 250. Jahrestag Friedrich Hölderlins mit der Ausstellung „Aufbrüche - Abbrüche. 250 Jahre Friedrich Hölderlin" im Frühjahr 2020 angemessen begehen. Besonderer Dank gilt der Baden-Württemberg Stiftung sowie dem Ministerium für Wissenschaft, Forschung und Kunst Baden-Württemberg für die weitreichende finanzielle Unterstützung. Nach ihrer Laufzeit in der Württembergischen Landesbibliothek werden Teile der Ausstellung von der Bibliothèque nationale et universitaire de Strasbourg übernommen. Im Fokus sollen hier ausgewählte Handschriften, die Frankreichreise Hölderlins sowie die französische Rezeption stehen.

Über eine vom Deutschen Literarturarchiv Marbach aufgebaute und betreute Plattform werden alle Veranstaltungen des Landes zentral beworben. Im Bereich der grafischen Gestaltung gibt es für das landesweite Hölderlin-Jubiläum einheitliche Standards (Logo etc.).

\section{Hölderlien. 2020}

Abb. 1: Logo Hölderlin 2020

Die große Jubiläumsausstellung der WLB entsteht auf der Grundlage der vielfältigen Sammlungen des Hölderlin-Archivs. Dazu gehören vor allem die bedeutendsten Bestände, die Werkhandschriften. Die Auswahl betrifft Dichtungen Hölderlins, die direkt oder indirekt in poetisch-thematischem Zusammenhang mit dem Stuttgarter Aufenthalt stehen: "An Landauer", "Das Ahnenbild”, „Der Gang aufs Land", "Stutgard" "Brod und Wein". Hinzu kommen die für die Bordeauxreise zentrale
Handschrift „Andenken“ und schließlich Briefe Hölderlins im Kontext der Aufenthalte in Stuttgart und Frankreich. Zahlreiche Exponate (Autografen, Drucke, Grafiken und Objekte) sollen Hölderlins Zeit in Stuttgart um 1800, seine Beziehungen zu Hegel und zu Susette Gontard sowie seine Reise nach Bordeaux dokumentieren. Im Mittelpunkt des Stuttgarter Aufenthalts steht Christian Landauer, bei dem er in dieser Zeit wohnte. Darüber hinaus richtet sich der Blick auch auf das revolutionäre Umfeld Hölderlins einschließlich der komplexen politischen Verwicklungen in den Folgejahren nach 1800. Hölderlins Gedichtentwurf "Dem Fürsten" trägt diesem Aspekt Rechnung. Neben der Stuttgart-Thematik bilden die Frankreichreise und der Bordeauxaufenthalt inhaltliche Schwerpunkte der Ausstellung.

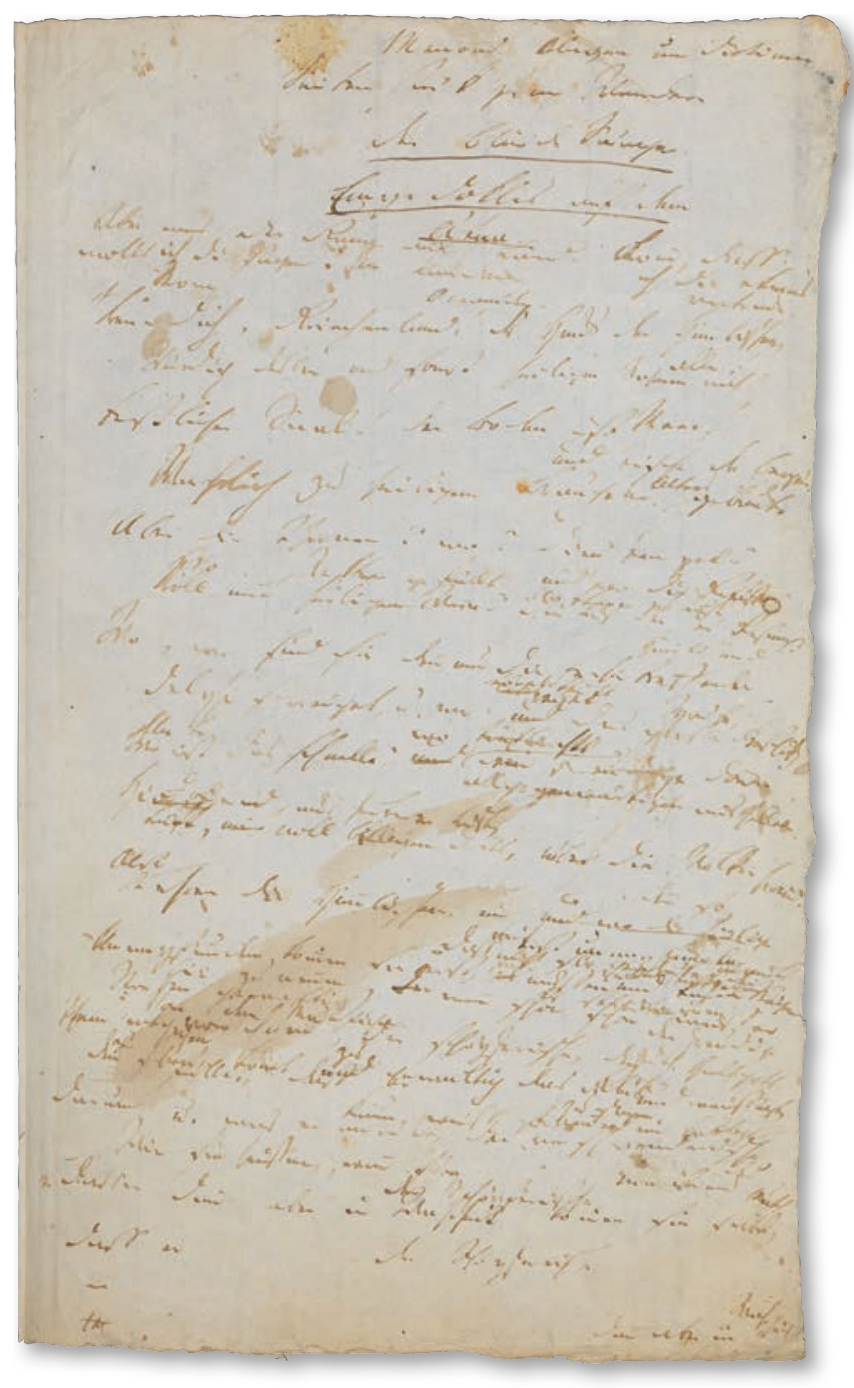

Abb. 2: Handschrift "Brod und Wein" 
Im Zusammenhang mit Susette Gontard werden ausgewählte Briefe präsentiert. Ihre Briefe, die Teil des Gok-Nachlasses sind, wurden mit Blick auf diese Ausstellung digitalisiert und in die Digitalen Sammlungen der WLB integriert. Sie bilden neben den bereits digitalisierten Hölderlin-Handschriften den Bereich „Hölderlin digital“. Dieser erhält eine wichtige Ergänzung durch ein aktuelles Projekt zum Homburger Folioheft, das die zeitliche Schichtung der einzelnen Entstehungsstufen transparent macht und in der Ausstellung erstmals der Öffentlichkeit zugänglich gemacht wird. Es werden dadurch interessante Einblicke in die „Dichterwerkstatt" Hölderlins geboten.

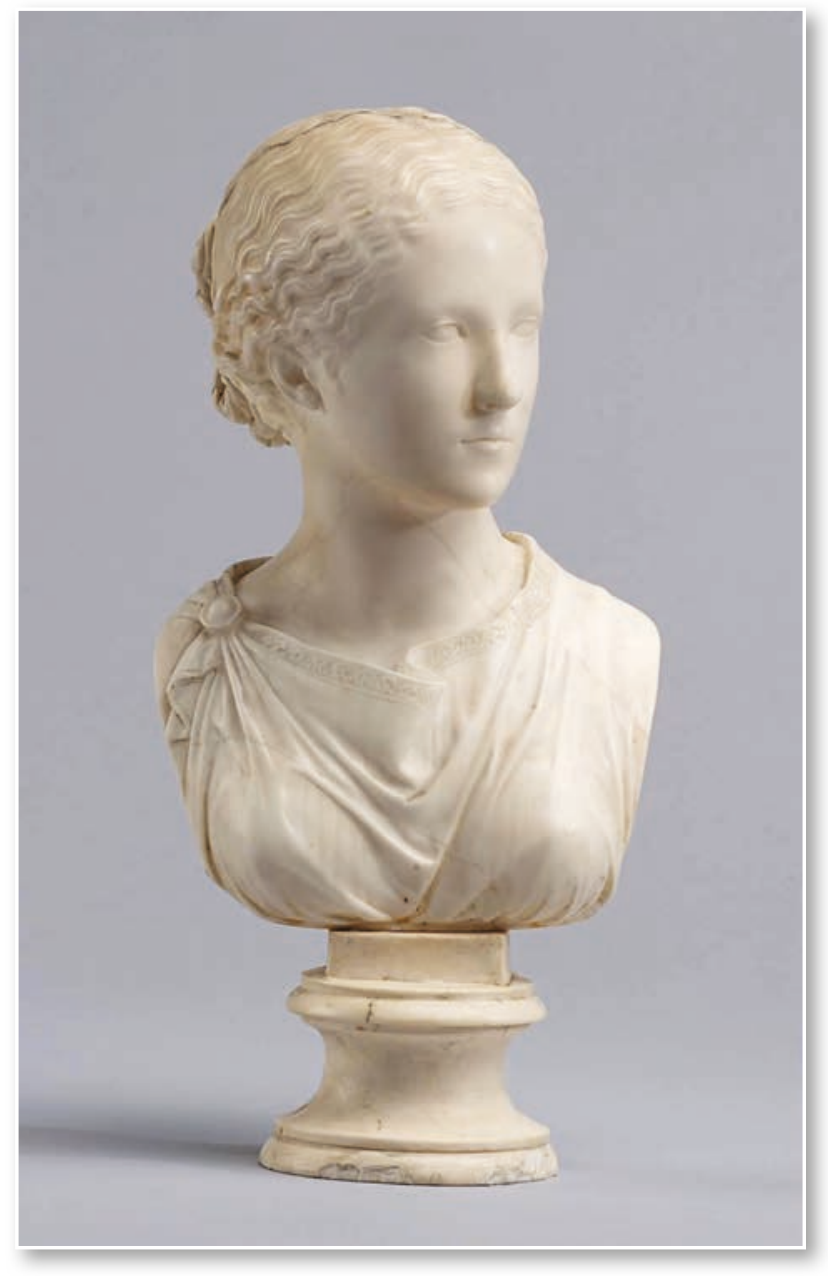

Abb. 3: Susette Gontard, Gipsabguss nach der Vorlage von Landolin Ohmacht
In der Ausstellung werden ferner Erstausgaben, wertvolle und bibliophile Drucke sowie besondere und bedeutende Übersetzungen präsentiert. Mit Blick auf den thematischen Schwerpunkt „Frankreich" stehen hier französische Übersetzungen im Vordergrund. Schlaglichter auf die spannende und vielfältige Rezeptionsgeschichte sollen die Wiederentdeckung Hölderlins durch Norbert von Hellingrath, die mannigfaltigen Facetten der Buchkunst und Druckgrafiken, die französische Rezeption sowie die Gedenkfeiern von 1870 bis heute werfen.

Ergänzt wird die Ausstellung durch ein abwechslungsreiches kulturelles Begleitprogramm (Vorträge, Lesungen, musikalische Veranstaltungen) in Abstimmung mit den landesweiten Aktivitäten. Ein reich bebilderter Begleitband liefert Beiträge zu den aufgeführten thematischen Bereichen und soll sowohl die breite Öffentlichkeit als auch das Fachpublikum ansprechen.

Eine ausführliche Beschreibung der Ausstellung einschließlich der vielfältigen Aktivitäten zu Hölderlin 2020 erwartet den Leser im kommenden WLBforum. Man darf gespannt sein.

Jörg Ennen 